EVS26

Los Angeles, California, May 6-9, 2012

\title{
Development of Fuel Economy Improvement by Using Driving Condition Prediction System for Hybrid Vehicle
}

\author{
Insup Kim ${ }^{1}$, Taesic Park, Buhmjoo Suh, Seokjoon Kim \\ ${ }^{1}$ Hyunda-Kia Motors, 772-1 Jangduk-Dong Hwaseong-Si Gyeonggi-Do South Korea, monjey@hyundai.com
}

\begin{abstract}
If the future driving condition such as road information and traffic condition can be predicted, the use of electrical power source will be controlled appropriately in order to improve the fuel economy of Hybrid vehicle. In this paper the algorithm for the driving condition prediction model and the rule-based controller for HEV are developed and verified through simulation and road test. With road information and traffic from 3D navigation, the types of road (uphill, flat or downhill) and the traffic condition (congestion or free driving) can be predicted by the Driving Condition Prediction System (DCPS). The rule-based controller for HEV can determine the control strategy (discharge-oriented, charge-oriented, or normal) depending on the future driving condition. With this technology the system can secure more battery capacity for regenerating when downhill is anticipated and engine can be operated within high efficiency area by discharging battery energy when uphill is anticipated. When congestion is predicted the battery is charged in advance in order to increase electric driving (EV) range and prevent inefficient series-path driving. Compared to the previous study, the methodology to determine future road condition and control strategy of HEV suggested in this paper is simple and fast enough to apply to real-time controller.
\end{abstract}

Keywords: HEV (hybrid electric vehicle), Navigation, Power management, City traffic, Control system

\section{Introduction}

Hybrid electric vehicle (HEV) can achieve better fuel economy and emit less pollution emission compared to conventional vehicle. Since it has two power sources - combustion engine and chemical battery - HEV has more room to improve system efficiency of power train by operating the combustion engine close to optimal area and recuperating braking energy, which charge the battery and propel the electric motor when high power demand, such as hill climbing and sudden acceleration, is requested

The most mass-manufactured control system of HEV is determined by the current system condition and the current driver's requirement; in that there is the case when HEV operate in low efficiency area because of unexpected high load condition or congestion. Uphill, downhill, and congestion make HEV overcharge or overdischarge HEV to minimum or maximum battery state of charge (SOC); thus it cannot operate efficiently and the performance of vehicle can be limited. Therefore if the driving condition such as road topology and congestion can be predicted, battery can have enough room to propel or generate electric motor; thus battery can be used more efficiently. For example once it is expected to meet down-hill, HEV discharges battery in advance to secure more room for battery in order to charge it more during down-hill. On the other 
hand once it is expected to meet congestion, the vehicle would use battery energy much because of increasing electric driving (EV); thus it can achieve better fuel economy by charging battery in advance. In these cases hybrid system controller with navigation data can reap benefit on fuel economy and performance respectively.

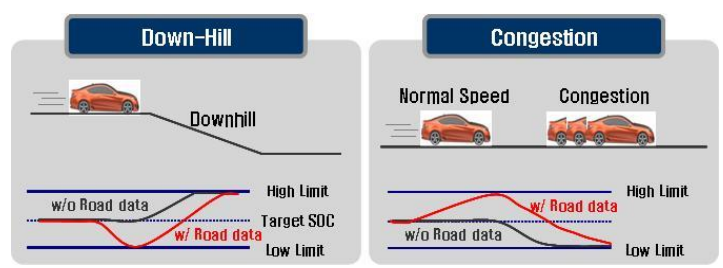

Figure1: HEV Control Scheme with future Road Slope and Speed information

Arun Rajagopalan studied a fuzzy-logic based parallel HEV control structure based on future driving condition. Traffic and elevation information from GPS over entire trip is used in an adaptive fuzzy logic controller (FLC) [1]. Yoshitaka Deguchi proposed a new HEV control system using car navigation information, which controls the charge/discharge of the battery [2]. Eric Hellstorm studied a real-time fuel-optimal cruise controller using road topology information. A model predictive control (MPC) scheme is used to control the longitudinal behaviour of the vehicle. By using discrete dynamic programming and a cost function, the fuel consumption can be reduced $2.5 \%$ on Swedish highway [3]. Beomsoo Kim studied the hybrid control system with the GPS system. This system classified road condition into three driving modes: Urban, Extraurban, and Highway, by travelling terrain and speed. With a dynamic programming approach, a rule-based controller was developed to obtain the optimal fuel economy and the optimal SOC trajectory [4].

The previous surveys had their limits in the way that the computation time is too long to apply to the mass-produced vehicle. In this paper we developed a new HEV controller with a driving condition prediction system, which has simple algorithm and less computation time. The future driving condition is anticipated by using moving average and bit counting methodologies and cooperated with the rule-based HCU controller. By using future road information, the Driving Condition Prediction System (DCPS) can determine the types of the driving condition (grade and traffic status) and sends control bit to hybrid control unit. A rule-based controller is developed and verified by simulation program,
PSAT (Power train Systems Analysis Toolkit). The DCPS is also implemented by using Labview, and the effectiveness of it is proven by conducting fuel economy test in real-world road.

\section{The System overview}

\subsection{The components of the system}

The overall system consists with the 3-dimension navigation, the DCPS and HEV controller.

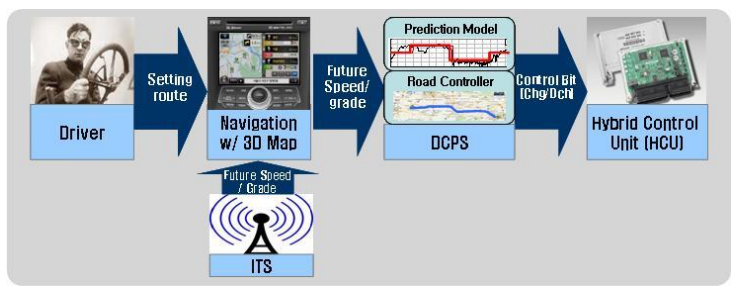

Figure2: Overview of the HEV system with DCPS

Unlike the conventional Navigation, 3D Navigation provides 3-dimension coordinate: altitude, longitude and height. Navigation developers, NAVTEC and Bosch, made 3D map for Europe and North America. Moreover traffic information within the selected route can be predicted by vehicle detection and tracking software [5], an optical digital camera image [6], and traffic information.

The DCPS has two features: driving condition prediction and road controller. With road topology and traffic information, the DCPS can evaluate road grade and traffic status; then the SOC levelling strategy of HEV controller is determined in advance for the future road. And after determining the control strategy for hybrid system, the road controller needs to track the position of the vehicle and sends the control bit (discharge / charge oriented control signal) to the HEV controller at right time. While travelling the selected route the road controller receives the current position from GPS and compares it with the pre-provided data. Once it detects that the vehicle is positioned at the predetermined position, the road controller sends the control bit to HEV controller.

\subsection{The New HEV Control strategy with the DCPS}

To improve the fuel economy and drivability of HEV the controller concept as below is applied.

- When Downhill is predicted the battery is discharged in advance to store more regenerative power 
- When Uphill is predicted the battery is charged in advance to have enough battery power preventing engine inefficient operating

- When Congestion is predicted the battery is charged in advance to secure enough battery power for Electric Driving (EV) and to prevent inefficient Series-Path driving

\section{Driving Condition Prediction System (DCPS)}

The role of the DCPS is to receive road topology and traffic information from 3D Navigation and to judge road shape (uphill, downhill, and flat) and congestion in the future. First, by using simulation and reference we define the decision criteria for road shape and congestion. And then we develop the mathematical equation in order to recognize the road shape and congestion. The algorithm of equation is shown as follows:

- Smoothing out road grade and speed data based on the pre-determined criteria

- Selecting the proper-sized window from the current position

- Using moving average method for road shape or bit counting method for congestion within the selected data.

\subsection{The Decision criteria for road shape and congestion}

Before developing the control bit for $\mathrm{HCU}$ control, we need to decide how much grade uphill or downhill is and how fast congestion is. Hence the decision criteria for road shape and congestion is determined and applied to calculate road grade $\mathrm{G}(\mathrm{k})$ at a given point ' $\mathrm{k}$ ' by using the raw coordinate data from $3 \mathrm{D}$ navigation. The requirement is suggested in Table 1 . If the given road does not satisfy the requirement the road grade $\mathrm{G}(\mathrm{k})$ is set to zero.

Table1: Requirement for the decision criteria

\begin{tabular}{|c|c|c|}
\hline & Requirement & Purpose \\
\hline Uphill & $\begin{array}{l}\text { Required Power }>\text { Engine } \\
\text { OOL Power }\end{array}$ & $\begin{array}{l}\text { To operate engine } \\
\text { in efficient area }\end{array}$ \\
\hline Downhill & $\begin{array}{c}\text { Regenerable Energy when } \\
\text { downhill > Energy (SOC } \\
\text { High - SOC Normal) }\end{array}$ & $\begin{array}{c}\text { To increase } \\
\text { regenerating } \\
\text { energy }\end{array}$ \\
\hline Congestion & $\begin{array}{c}\text { Regenerable Energy when } \\
\text { downhill < Energy (SOC } \\
\text { Normal - SOC Low) }\end{array}$ & $\begin{array}{l}\text { To secure battery } \\
\text { energy for Electric } \\
\text { Driving (EV) }\end{array}$ \\
\hline
\end{tabular}

We can determine uphill if the required power of vehicle surpassed the engine optimal operating line (OOL) power. In this case the engine will be operated in inefficient area if there is not enough battery energy; therefore the vehicle needs to charge battery in advance to prevent this. In addition we can determine downhill if the charge energy during the downhill is enough to charge the battery fully; in other words the condition when battery will be expected to meet maximum SOC, is downhill

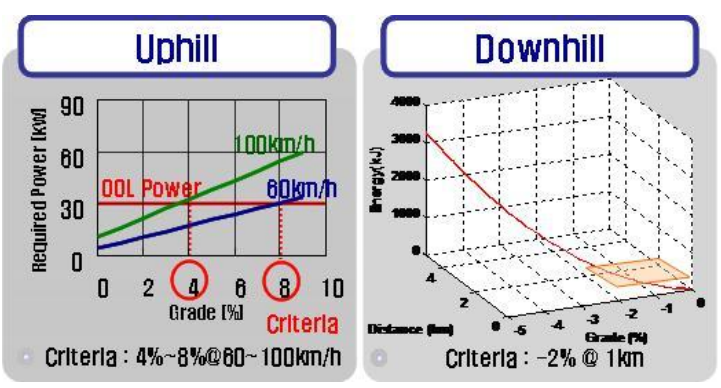

Figure3: Decision Criteria for Uphill and Downhill

Congestion is determined by the average speed of a certain period, and the criteria of speed is quoted as Table2 [7]. When the average speed within a certain area is below $25 \mathrm{~km} / \mathrm{h}$, congestion is considered.

Table2: Decision Criteria for Congestion

\begin{tabular}{|c|c|}
\hline Average Speed & Traffic Status \\
\hline Above $65 \mathrm{~km} / \mathrm{h}$ & Free Flow \\
\hline $25 \sim 65 \mathrm{~km} / \mathrm{h}$ & Near Capacity \\
\hline $10 \sim 25 \mathrm{~km} / \mathrm{h}$ & Congestion \\
\hline $0 \sim 10 \mathrm{~km} / \mathrm{h}$ & Jam Status \\
\hline
\end{tabular}

\subsection{Road Shape Recognition}

With road shae criteria we develop the mathematical equation for road shape recognition by using the moving average and bit counting methodologies. And the determined criteria of distance decide sampling size of data. The equation used for road shape recognition is as below.

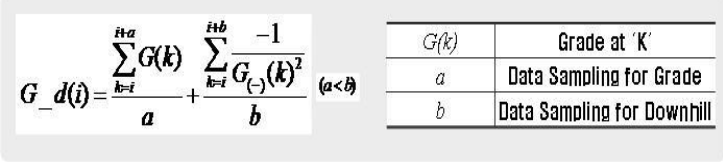

Figure4: Equation for Road Shape Recognition

Where $\mathrm{G}(\mathrm{k})$ is calculated by the decision criteria and ' $a$ ' and ' $b$ ' are the number of data sampling for grade and downhill respectively. The reason why there is a equation for downhill, is that the criteria of downhill is different from that of uphill. Through the real road data analysis, ' $a$ ' is determined as $500 \mathrm{~m}$ and ' $\mathrm{b}$ ' is determined as $1 \mathrm{~km}$. 
Consequently, the control bit for the SOC levelling strategy of HEV controller can be calculated in advance for a route designated by a driver according to the obtained G_d(i). Fig. 5 shows the calculation results of the control bits determining Charge-oriented control $(\mathrm{Bit}=1)$, Discharge-oriented control (Bit $=-1)$, and Normal control $(\mathrm{Bit}=0)$.

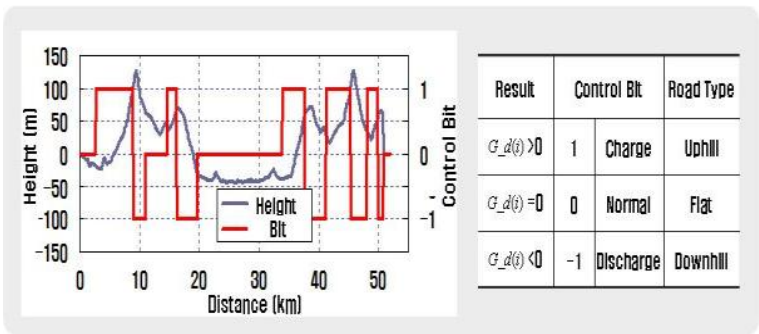

Figure5: Result for Road shape recognition

\subsection{Congestion Recognition}

The congestion is determined by counting the number of Congestion and Jam status (below $25 \mathrm{~km} / \mathrm{h}$ ) within a certain period. The equation consists of Future congestion bit $\left(\mathrm{L}_{\mathrm{bit}}\right)$ and Current congestion bit $\left(\mathrm{S}_{\mathrm{bit}}\right)$ as follows.

\begin{tabular}{|c|c|c|c|}
\hline & uture Congestlon & \multicolumn{2}{|l|}{ Current Congestion } \\
\hline \multicolumn{2}{|c|}{$\begin{array}{l}L=C_{k=i}^{i+c} \text { ount } C(k) \\
L_{b i t}=\left\{\begin{array}{l}1(L>e) \\
0(L<e)\end{array}\right.\end{array}$} & \multicolumn{2}{|c|}{$\begin{array}{l}S=\operatorname{Count}_{k=i}^{i+d} C(k) \\
S_{b i t}=\left\{\begin{array}{l}1(S>f) \\
0(S<f)\end{array}\right.\end{array}$} \\
\hline & \multicolumn{2}{|c|}{ Description } & Value \\
\hline Count $C(x)$ & \multicolumn{2}{|c|}{ Counting the number of congestion from position ' $\mathrm{K}$ ' } & - \\
\hline$c$ & \multicolumn{2}{|c|}{ Distance of counting for future congestion } & $7 \mathrm{~km}$ \\
\hline$d$ & \multicolumn{2}{|c|}{ Distance of counting for current congestion } & $2 \mathrm{~km}$ \\
\hline$e$ & \multicolumn{2}{|c|}{ Criteria for determination of future congestion } & $3 \mathrm{~km}$ \\
\hline$f$ & Criteria for determin & current congestion & $500 \mathrm{~m}$ \\
\hline
\end{tabular}

Figure6: Equation for Congestion recognition

$C(k)$ is the congestion decision bit at point ' $k$ ' and it is ' 1 ' when vehicle speed is less than $25 \mathrm{~km} / \mathrm{h}$. Count function is to summate $\mathrm{C}(\mathrm{k})$. For example within $7 \mathrm{~km}$ from the current vehicle position we count the distance that is congestion and if the congestion distance is less than $3 \mathrm{~km}$ we expect the congestion in the future. Fig. 7 shows the calculation results of the HEV's control bits with the traffic status information and equation.

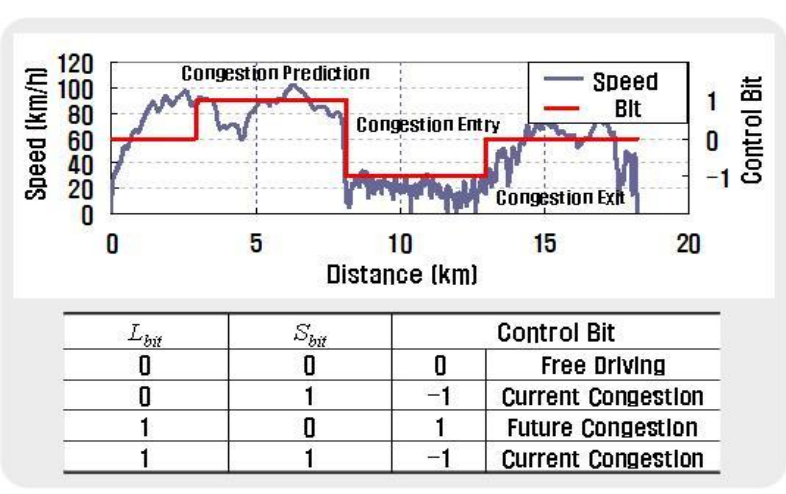

Figure7: Result for Congestion recognition

\subsection{Road Controller}

The role of road controller is tracking the current position and sending HEV control bit predetermined at the right time. The method to track the current position is comparing the saved the coordinated data and the current data and choosing the closest point. This is treated with considerable detail in Section 5.

\section{Development of New HEV Control system with the DCPS}

A Hyundai Sonata HEV was used for the HEV models in the simulator and as a test vehicle for conducting driving tests. This HEV consists of engine, electric motor, lithium ion battery and engine clutch. The engine clutch allows it electric driving (EV) and the electric motor and battery allow it to regenerate during braking and engine to operate at optimal area. The specifications of the components are shown in Table 3.

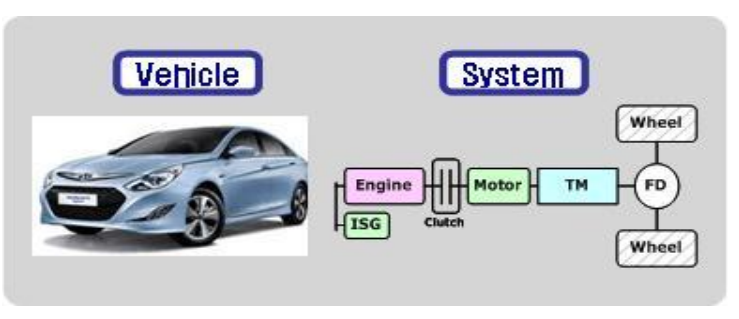

Figure8: Configuration of Sonata Hybrid Power Train

Table3: Specification of the HEV components

\begin{tabular}{|l|c|}
\hline Engine & 4-cylinder 2.4 L Gasoline Engine \\
\hline Motor & PMSM Motor, Max Power: 30kW \\
\hline Transmission & 6Automatic Transmission \\
\hline Battery & Li-ion battery, Capacity: 5.3Ah \\
\hline
\end{tabular}




\subsection{Rule-baesd HEV Control Algorithm with DCPS}

The current battery SOC management is different according to SOC range (low, middle, and high) to maintain proper SOC level. In new control system, SOC criteria for low and high SOC range is changed depending on the control bit from DCPS and to do so, the engine on/off and power distribution between engine and battery has changed as shown in Fig 9..

Table4: Basic rules of the HEV Controller for DCPS

\begin{tabular}{|l|c|c|c|}
\hline & Uphill & Flat & Downhill \\
\hline Congestion & Charge & Charge & Charge \\
\hline Free Driving & Charge & Normal & Discharge \\
\hline
\end{tabular}

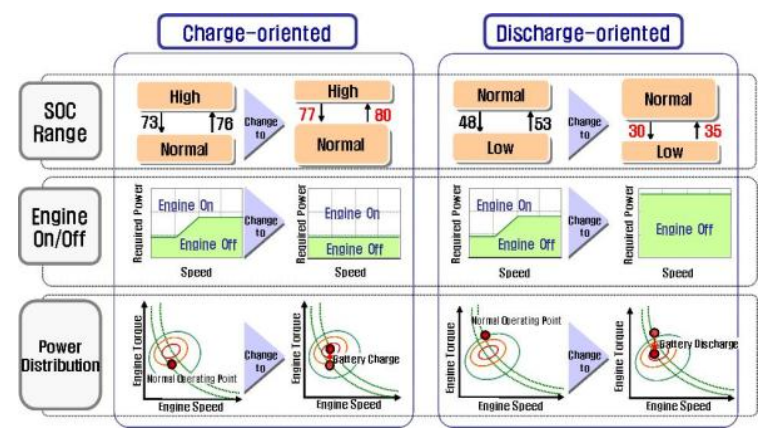

Figure9: The Rule-based HEV Controller Strategy

\subsection{Simulation}

The simulation is conducted to prove and verify the result of the proposed control system. The simulation program, PSAT (Power train Systems Analysis Toolkit) is used with Hyundai Sonata HEV model. Real-road information is obtained near Gangwon province (where has a plethora of hills) and Seoul urban road (where has traffic jam frequently) in Korea.

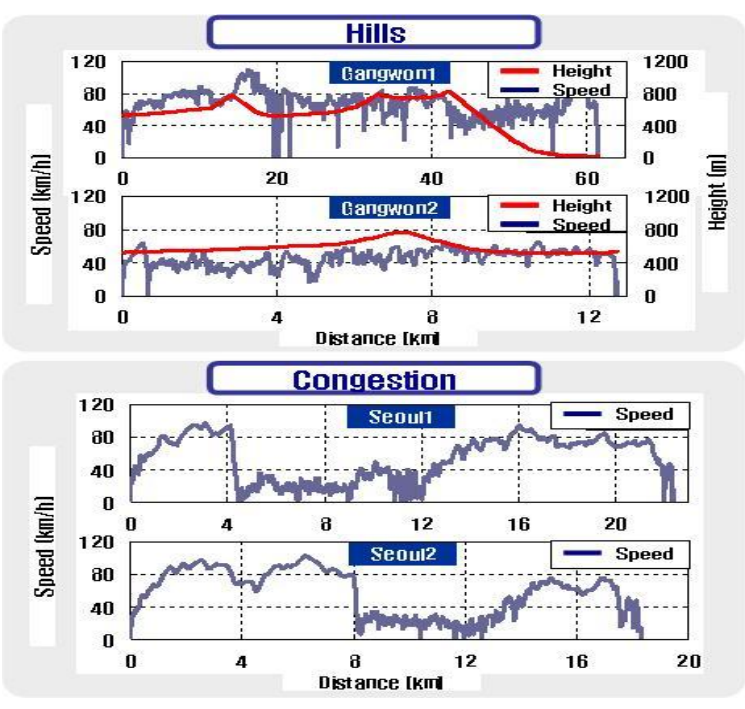

Figure10: Simulation driving cycle (Hills and Urban)

\subsubsection{Simulation result of Hills vicinity}

The vicinity of Gangwon in Korea has a plethora of uphill and downhill courses. The simulation results using these data, is shown as below. The DCPS allows the battery to secure enough space to store electric energy before entering downhill course. In addition it allow engine to avoid operating in less efficient point. Thus the vehicle can store more electric energy during regenerating and has better engine efficient compared to the vehicle without the DCPS; then the fuel economy is improved by from 3.4 to $5.6 \%$.

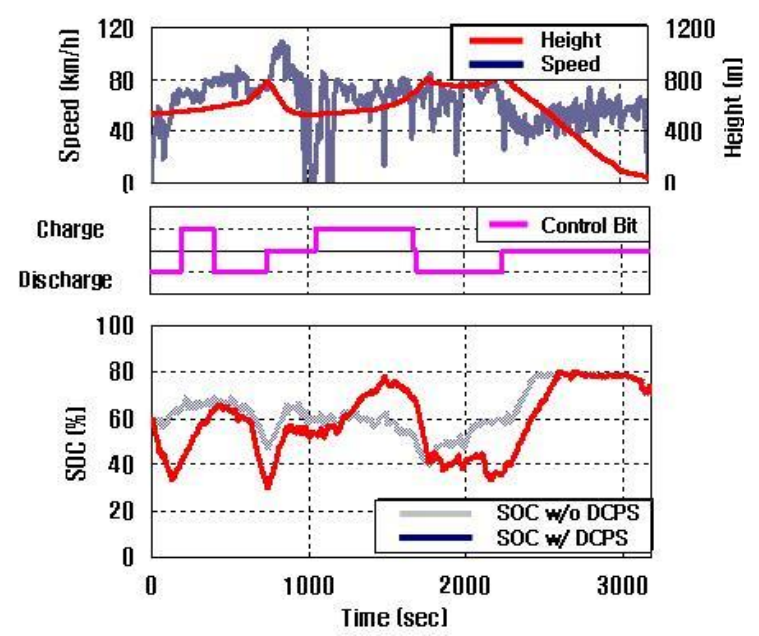

Figure11: Simulation results of Hills (Gangwon1)
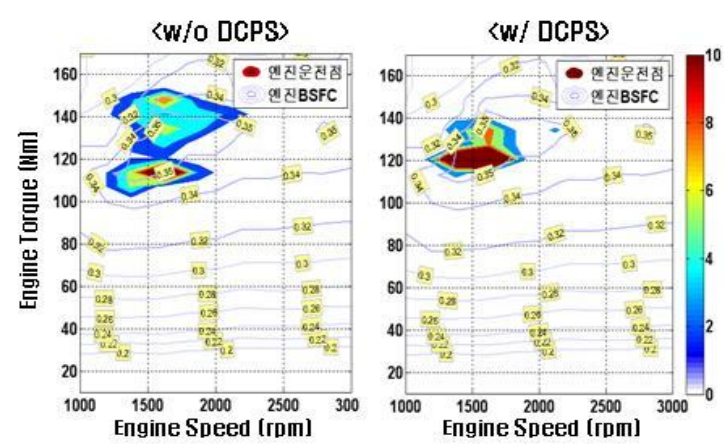

Figure12: Engine Operation area of Hills (Gangwon1)

Table5: Simulation result for Hills

\begin{tabular}{|c|c|c|c|c|c|}
\hline \multirow{2}{*}{} & \multicolumn{2}{|c|}{ Gangwon1 } & \multicolumn{2}{c|}{ Gangwon2 } \\
\cline { 2 - 6 } & $\begin{array}{c}\text { w/o } \\
\text { DCPS }\end{array}$ & w/ DCPS & $\begin{array}{c}\text { w/o } \\
\text { DCPS }\end{array}$ & w/DCPS \\
\hline \multicolumn{2}{|c|}{ FE $(\mathrm{km} / \mathrm{l})$} & 19.6 & $\begin{array}{c}20.7 \\
(5.6 \%\end{array}$ & 14.6 & $\begin{array}{c}15.1 \\
(5.6 \% \uparrow)\end{array}$ \\
\hline \multicolumn{2}{|c|}{ Regen Energy (kJ) } & 5004 & 6203 & 2820 & 3037 \\
\hline \multicolumn{2}{|c|}{ Engine Eff. (\%) } & 33.7 & 34.0 & 31.2 & 32.0 \\
\hline \multirow{2}{*}{ Grade } & Max & \multicolumn{2}{|c|}{$7.0 \%$} & \multicolumn{2}{c|}{$15.8 \%$} \\
\cline { 2 - 6 } & Min & \multicolumn{2}{|c|}{$-9.1 \%$} & \multicolumn{2}{c|}{$-11.8 \%$} \\
\hline
\end{tabular}




\subsubsection{Simulation result of the urban road}

Urban road's speed is measured in the rush hour to conduct simulation. The congestion distance is from $4 \mathrm{~km}$ to $8 \mathrm{~km}$ and the average speed is $16 \mathrm{~km} / \mathrm{h}$. The reason why I choose this route is that HEV has low system efficient at low speed. Once it reaches minimum SOC, the vehicle operate in the Series-mode, which StarterGenerator generate electricity and motor propels the vehicle simultaneously. At this mode the engine operates at low efficient area and the power path becomes long; then it result in low system efficient.

With the DCPS the congestion can be predicted in advance, so it secures more battery energy for electric-driving. This leads to reduce the series driving and increase system efficiency of HEV as shown Table 6.; then the fuel economy is improved by from 6.3 to $9.3 \%$.
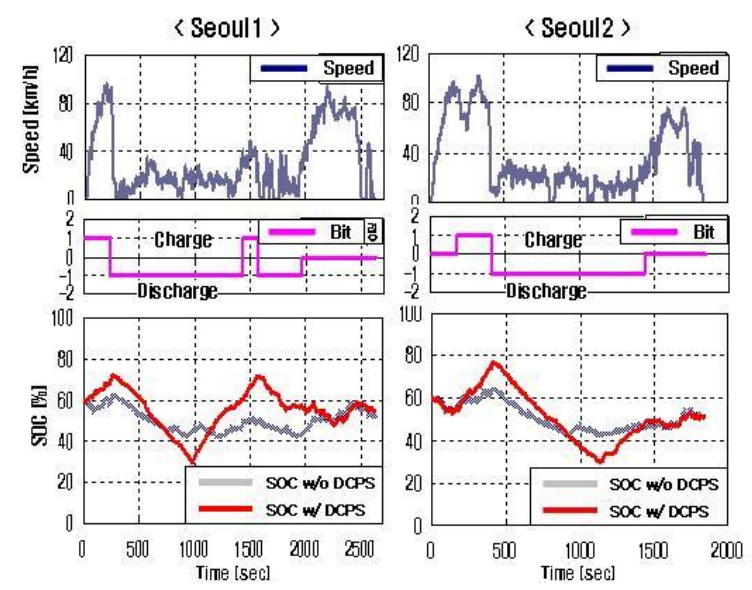

Figure13: Simulation results of Congestion (Seoul1,2)

Table6: Simulation result of Congestion

\begin{tabular}{|c|c|c|c|c|}
\hline & \multicolumn{2}{|c|}{ Seoul 1 } & \multicolumn{2}{c|}{ Seoul 2 } \\
\cline { 2 - 5 } & $\begin{array}{c}\text { w/o } \\
\text { DCPS }\end{array}$ & w/ DCPS & $\begin{array}{c}\text { w/o } \\
\text { DCPS }\end{array}$ & w/ DCPS \\
\hline FE (km/l) & 15.1 & $\begin{array}{c}16.5 \\
(9.3 \% \uparrow)\end{array}$ & 16.0 & $\begin{array}{c}17.0 \\
(6.3 \% \uparrow)\end{array}$ \\
\hline $\begin{array}{c}\text { Idle Charge } \\
\text { (sec) }\end{array}$ & 482 & 197 & 376 & 272 \\
\hline $\begin{array}{c}\text { Electric- } \\
\text { driving. (sec) }\end{array}$ & 624 & 940 & 596 & 782 \\
\hline
\end{tabular}

\section{Prototype and test result}

The prototype of the DCPS is made by using Labview program and GPS sensor. The road topology and traffic information of the selected routes are saved and the DCPS and the road controller is implemented by using the Labview program. While travelling the route, the DCPS receives the position information from GPS and compares the current position with the routed data. Once it detects that the vehicle is poisoned at the predetermined position, the controller send the charge or discharge signal to hybrid control unit to change the operating strategy.

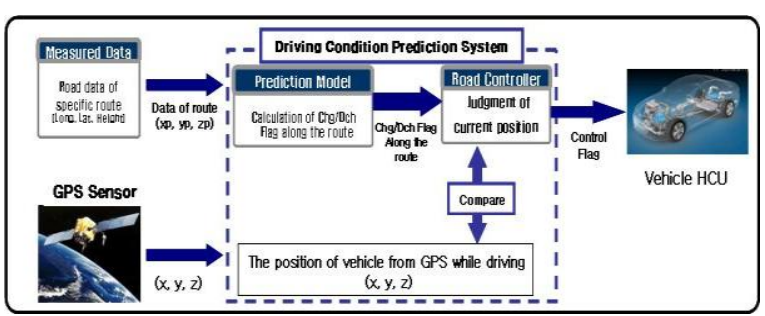

Figure14: Driving Condition Prediction System (DCPS) Prototype schematic

In order to evaluate the fuel economy improvement, two test vehicles with and without the DCPS are accompanied on the test road (Gangwon1/2, Seoul1/2). The real road test shows similar result with simulation as shown in Table 7.

Table7: Fuel economy improvement of Test and simulation using DCPS for Sonata Hybrid

\begin{tabular}{|c|c|c|c|}
\hline \multicolumn{2}{|c|}{ Driving Route } & Test & Simulation \\
\hline \multirow{2}{*}{ Hills } & Gangwon1 & $5.0 \%$ & $5.6 \%$ \\
\cline { 2 - 4 } & Gangwon2 & $3.6 \%$ & $3.4 \%$ \\
\hline \multirow{2}{*}{$\begin{array}{c}\text { Conge } \\
\text {-stion }\end{array}$} & Seoul1 & $9.2 \%$ & $9.3 \%$ \\
\cline { 2 - 4 } & Seoul2 & $5.5 \%$ & $6.3 \%$ \\
\hline
\end{tabular}

\section{Conclusion}

This paper has presented the driving condition prediction control algorithm for the HEV and the rule-based control strategy with road information is suggested. The proposed algorithm and strategy was also implemented and verified through simulations and vehicle tests. The major conclusions of this investigation are shown as follows:

- The technique for handling the road topology data and traffic data is suggested and the criteria and the mathematical equation for the Driving Condition Prediction System (DCPS) is proposed.

- The rule-based controller for HEV by using the DCPS is proposed. Depending on the road shape (uphill, flat and downhill) and the traffic condition (congestion and free driving) the control strategy for HEV is determined to charge, normal, or discharge. With DCPS the HEV secure more capacity to charge or discharge the battery. 
- The fuel economy improvement of the DCPS is proven by simulation and road test. Compared with a conventional system, the fuel economy was improved by from $3.6 \%$ to $5.0 \%$ in the vicinity of hills and by from $5.5 \%$ to $9.2 \%$ in congestion.

- Compared to the previous works, in this paper the simple and fast methodology to determine the road condition and the control strategy is developed. It is enough to adapt to real-time controller.

\section{References}

[1] Arun Rajagopalan, Gregory Washington, Intelligent Control of Hybrid Electric Vehicle Using GPS Information, SAE, 2002-01-1936, 2002

[2] Yoshitaka Deguchi, Kouichi Kuroda, Makto Shouji, Taketosh Kawabe, HEV Charge/Discharge Control System Based on Navigation Information, SAE, 2004-210028, 2004

[3] Erik Hellstorm, Anders Froberg, Lars Nielsen, A Real-Time Fuel-Optimal Cruise Controller for Heavy Trucks Using Road Topology Information, SAE, 2006-01-0008, 2006

[4] Beomsoo Kim et. Al., HEV Cruise Control Strategy on GPS (Navigation) Information, World Electric Vehicle Journal Vol. 3, ISSN 2032-6653, 2009

[5] Pongpaibool P. et. Al., Evaluation of Road traffic congestion using fuzzy techniques, Proceeding of IEEE TENCON 2007, Taipei, Taiwan, IEEE, 2007

[6] G. Palubinskas et. Al., Detection of Traffic Congestion in Optical Remote Sensing Imagery, Geoscience and Remote Sensing Symposium, IEEE, 2008

[7] Jongtak Kim, Jintak Choi, Design and Implementation for Incident Detection Algorithm in Intelligent Transportation System, J. KSIAM IT series Vol. 8, No.1, 79-90, 2004

\section{Authors}

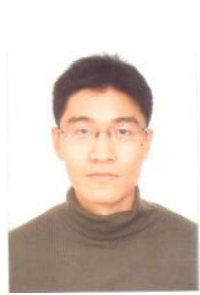

Insup Kim is a research engineer of Eco-car System Test Team at Hyundai Motor Company. He has studied from HEV to PHEV to EV since 2006. He received bachelor's degree in School of Mechanical and Aerospace Engineering from Seoul National University, South Korea, in 2006.

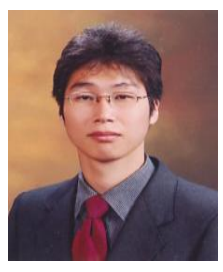

Taesic Park is a research engineer of Eco-car System Test Team at Hyundai Motor Company. He has studied from HEV to PHEV to EV since 2006. He received bachelor's degree in School of Mechanical Engineering from Busan National University, South Korea, in 2006.

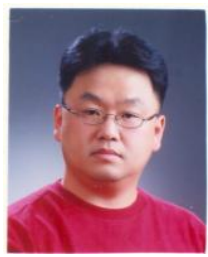

Buhmjoo Suh is a senior research engineer of Eco-car System Test Team at Hyundai Motor Company. $\mathrm{He}$ received a $\mathrm{Ph} . \mathrm{D}$. degree in School of Mechanical Engineering from University of Califonia, David, United States.

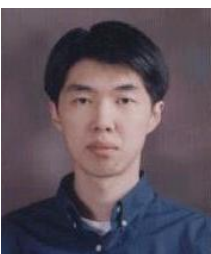

Seokjoon Kim is a senior research engineer of Eco-car System Test Team at Hyundai Motor Company. $\mathrm{He}$ received bachelor's degree and a M.S. degree in School of Mechanical Engineering from Seoul National University, South Korea. 